\title{
Plant Glandular Trichomes as Targets for Breeding or Engineering of Resistance to Herbivores
}

\author{
Joris J. Glas ${ }^{1}$, Bernardus C. J. Schimmel ${ }^{1}$, Juan M. Alba ${ }^{1}$, Rocío Escobar-Bravo ${ }^{2}$, \\ Robert C. Schuurink ${ }^{3}$ and Merijn R. Kant ${ }^{1, *}$
}

1 Department of Population Biology, Institute for Biodiversity and Ecosystem Dynamics, 1098 XH Science Park 904, Amsterdam, The Netherlands; E-Mails: j.j.glas@uva.nl (J.J.G.); b.c.j.schimmel@uva.nl (B.C.J.S.); j.m.albacano@uva.nl (J.M.A.)

2 Department of Plant Breeding, Subtropical and Mediterranean Horticulture Institute "La Mayora" (IHSM), Spanish Council for Scientific Research (CSIC), Experimental Station "La Mayora", E-29750, Algarrobo-Costa, Málaga, Spain; E-Mail: rocio.escobar@eelm.csic.es

3 Department of Plant Physiology, Swammerdam Institute of Life Sciences, 1098 XH, Science Park 904, Amsterdam, The Netherlands; E-Mail: r.c.schuurink@uva.nl

* Author to whom correspondence should be addressed; E-Mail: m.kant@uva.nl; Tel.: +31-20-5257-793; Fax: +31-20-5257-754.

Received: 6 November 2012; in revised form: 28 November 2012 / Accepted: 5 December 2012 / Published: 12 December 2012

\begin{abstract}
Glandular trichomes are specialized hairs found on the surface of about $30 \%$ of all vascular plants and are responsible for a significant portion of a plant's secondary chemistry. Glandular trichomes are an important source of essential oils, i.e., natural fragrances or products that can be used by the pharmaceutical industry, although many of these substances have evolved to provide the plant with protection against herbivores and pathogens. The storage compartment of glandular trichomes usually is located on the tip of the hair and is part of the glandular cell, or cells, which are metabolically active. Trichomes and their exudates can be harvested relatively easily, and this has permitted a detailed study of their metabolites, as well as the genes and proteins responsible for them. This knowledge now assists classical breeding programs, as well as targeted genetic engineering, aimed to optimize trichome density and physiology to facilitate customization of essential oil production or to tune biocide activity to enhance crop protection. We will provide an overview of the metabolic diversity found within plant glandular trichomes, with the emphasis on those of the Solanaceae, and of the tools available to manipulate their activities for enhancing the plant's resistance to pests.
\end{abstract}


Keywords: glandular trichome; plant-herbivore interactions; pathogen; Solanaceae; pest resistance; plant defense; leaf hair; tomato; plant breeding; genetic engineering

\section{Introduction}

Virtually all plant species possess some kind of hair-like epidermal structures. When these structures are present on the aerial parts of a plant, they are commonly referred to as trichomes, while similar outgrowths from the root are called root hairs. Trichomes - the term deriving from the Greek word "trichos", which means hair-are, in most cases, not connected to the vascular system of the plant, but instead are extensions of the epidermis from which they originate [1]. Trichomes range in size from a few microns to several centimeters and they exhibit a tremendous species-specific diversity in shape (for examples, see [2]), and, therefore, they are often used as diagnostic characteristics for the identification of plant species, e.g., [3]. Trichomes are mainly found on leaves and stems, but they can also occur, depending on the species, on petals, petioles, peduncles and seeds [1]. Trichomes can be single-celled or multicellular, but the criterion that is mostly used to classify them is whether they are glandular or not [4]. Non-glandular trichomes are present on most angiosperms, but also on some gymnosperms and bryophytes [1]. On the model plant Arabidopsis, only non-glandular trichomes can be found, which are unicellular and can be either unbranched, or have two to five branches [5]. These trichomes are polyploid [6] and have been extensively studied with respect to their development, e.g., [7]. In contrast, glandular trichomes are usually multicellular, consisting of differentiated basal, stalk and apical cells and can be found on approximately $30 \%$ of all vascular plants [8]. Glandular trichomes have in common the capacity to produce, store and secrete large amounts of different classes of secondary metabolites [8,9]. Many of the specialized metabolites that can be found in glandular trichomes have become commercially important as natural pesticides, but also have found use as food additives or pharmaceuticals [10,11]. For instance, plants of the Lamiaceae, comprising species such as mint (Mentha x piperita), basil (Ocimum basilicum), lavender (Lavandula spica), oregano (Origanum vulgare) and thyme (Thymus vulgaris), are cultivated for their glandular trichome-produced essential oils [9]. Moreover, artemisinin, a sesquiterpene lactone that is produced in the glandular trichomes of annual wormwood (Artemisia annua), is used for the treatment of malaria [12]. In addition, gossypol and related compounds, which are dimeric disesquiterpenes produced by cotton (Gossypium hirsutum) trichomes, have strong antifungal activity [13] and are potential natural pesticides [14]. It is for these kinds of specialized metabolic properties, and for the opportunities to modify these properties via genetic engineering, e.g., [15], that trichomes have received increased attention over the past years [16]. By means of this review article, we will provide an introduction into trichome biology, thereby focusing on the biosynthesis and biochemistry of the main trichome-produced compounds, as well as their role in plant resistance. Also, we summarize some approaches that have been undertaken to engineer the metabolism of trichomes, especially those of mint, tobacco (Nicotiana spp.) and tomato (Solanum spp.). 


\section{Trichome Morphology in Mint, Basil and Tomato}

Glandular trichomes can be subdivided in capitate and peltate trichomes. Both types are frequently present in, for example, the Asteraceae, Lamiaceae and Solanaceae. Capitate trichomes typically consist of one basal cell, one to several stalk cells, and one or a few secretory cells at the tip of the stalk [17]. They predominantly produce non-volatile or poorly volatile compounds that are directly exuded onto the surface of the trichome [16]. Peltate trichomes, of which typical examples can be found in mint and basil, consist of a basal cell, one (short) stalk cell, and a head consisting of several secretory cells, which is surmounted by a large sub-cuticular storage cavity. This cavity is formed by separation of the cuticle from the cell wall of the secretory cells [18] and it is filled with the products of the secretory cells, thereby giving these trichomes a characteristic "bulb-like" shape [18]. Cell walls of stalk cells are usually cutinized, presumably to prevent contact of trichome-produced compounds, which can be autotoxic, with other parts of the plant [19].

The trichomes of the Solanaceae have been studied in detail, especially those of Solanum species, because of their role in plant resistance. The morphology of the Solanum spp. trichomes was originally described by Luckwill [20], but later revised by Channarayappa et al. [21]. Typically, eight different types are distinguished of which four (i.e., type I, IV, VI and VII) are glandular capitate trichomes and four (i.e., type II, III, V and VIII) are non-glandular (Figure 1). Of the glandular trichomes, type I and IV are capitate, whereas type VI and VII are globular. The glandular trichome types differ in number of stalk and secretory cells (see Table 1 for a description of trichome morphology), as well as in their chemical contents.

Figure 1. Glandular trichomes in section Lycopersicon. Wild accessions have high densities of glandular trichomes that confer resistance to several pests. Panel (A) shows the leaflet surface of Solanum habrochaites acc. LA 1777 with high densities of glandular trichome types IV and VI (B), and type I (C). Surface of Solanum pennellii acc. LA 716 is also covered by type IV trichomes (D, E) producing and secreting acyl sugars. This accession also has type VI trichomes, but in low density (F). Panel (G) shows the surface of Solanum lycopersicum cv. Moneymaker. Cultivated tomato has low density of type VI trichomes $(\mathbf{H})$ and type I trichomes. Sometimes, type IV-like trichomes (I) are observed on stems, veins, and on the leaflet edges. White bars represent $500 \mu \mathrm{m}$ in panel A, C, D, and G. In panels B, E, F, H, and I, bars represent $50 \mu \mathrm{m}$.
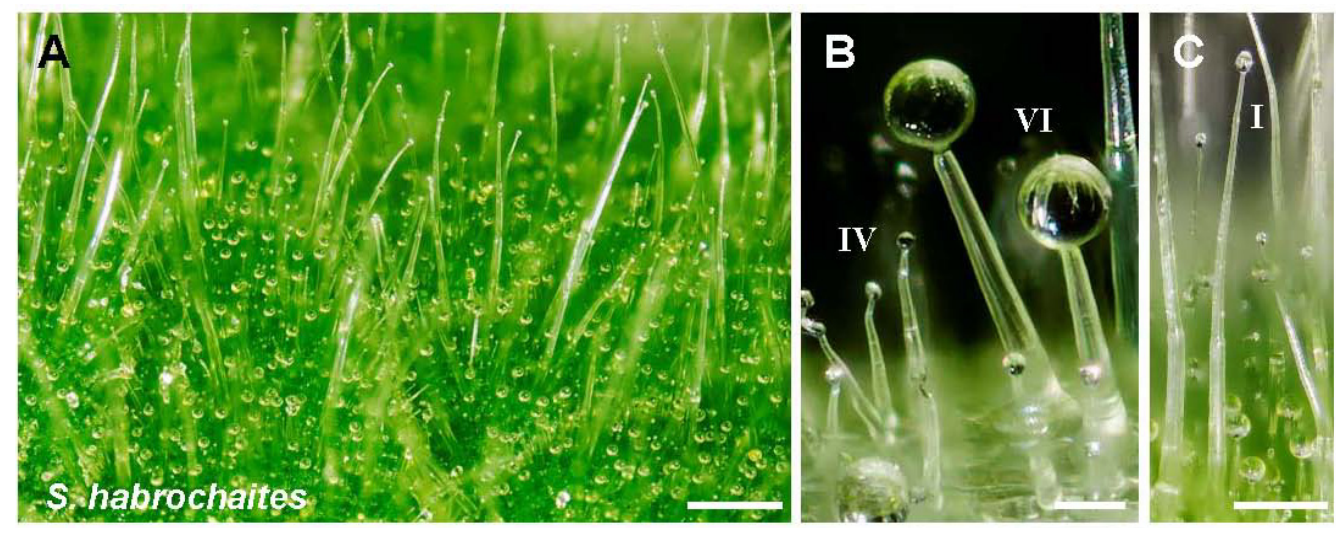
Figure 1. Cont.
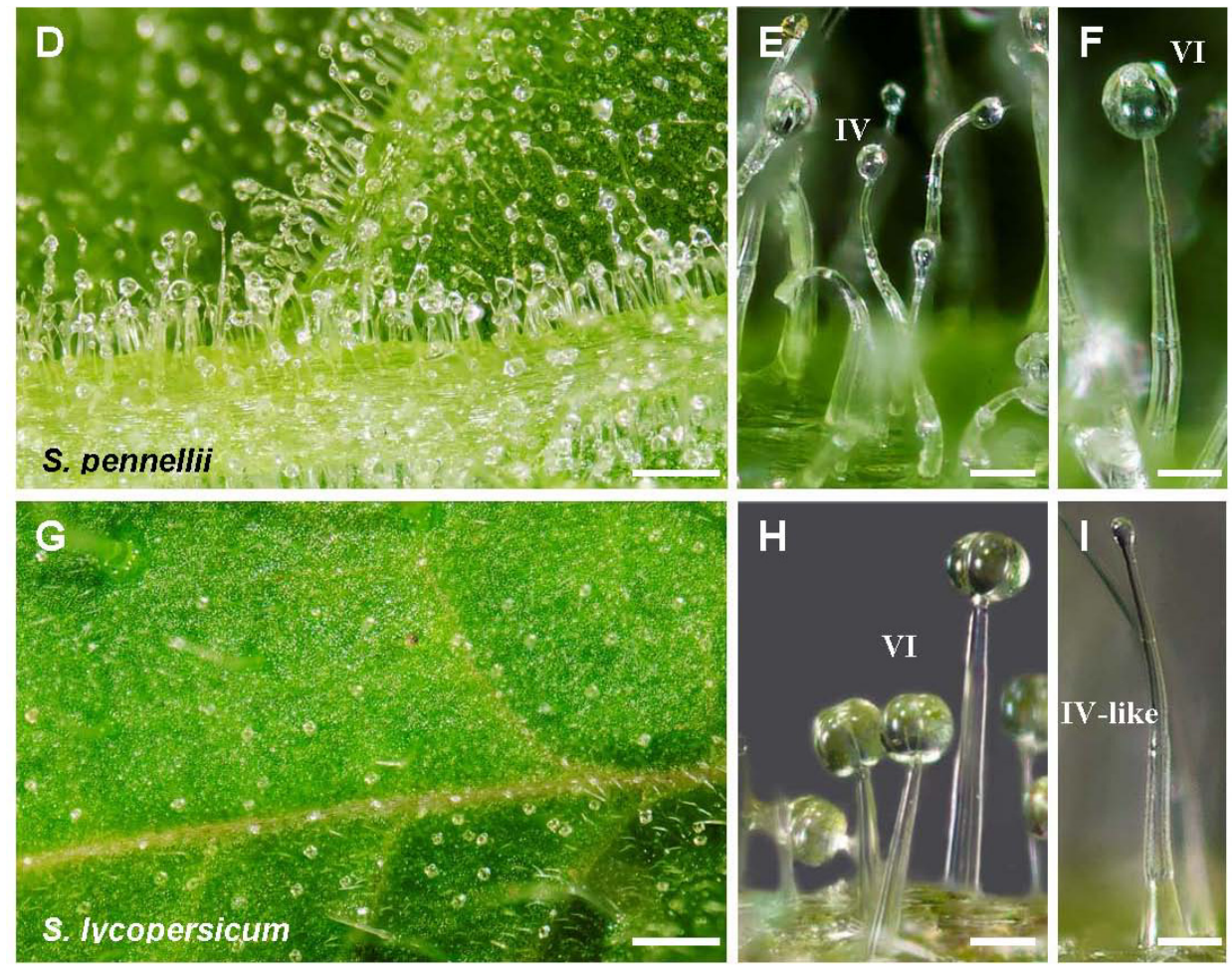

Table 1. Trichome description according to Luckwill [20] and revised by Channarayappa et al. [21].

Thin glandular trichomes consisting of $6-10$ cells and $2-3 \mathrm{~mm}$ long. Globular
and multicellular base with a small and round glandular cell in the trichome tip.


For example, in the cultivated tomato (Solanum lycopersicum), type I trichomes contain mostly acyl glucoses, while type VI trichomes from this species contain terpenoids. Furthermore, the same trichome type can have different content in different tomato species [22]. Trichome type I and IV, which, according to some authors may actually represent the same type, look physically similar to non-glandular trichomes, but they differ by the presence of one or two glandular cells in the tip, which secrete acyl sugars [22]. Type VI glandular trichomes are composed of four secretory cells on a two-celled stalk which secrete metabolites that are stored under a waxy cuticle [22]. In the cultivated tomato, type VI trichomes contain monoterpenes [23,24] as well as a number of sesquiterpenes [24,25]. Interestingly, transcript analysis indicated that both type I and IV, as well as type VI, across Solanum species, express many of the genes necessary for acyl sugar, flavonoid and terpenoid production [22]. Type VII glandular trichomes, which are less abundant, consist of a small multicellular glandular head that is situated on a short one-celled stalk [21]. It has been suggested that type VII glandular trichomes of Solanum habrochaites are less involved in the biosynthesis of secondary metabolites but instead may have other functions, for instance, protease inhibitor synthesis and storage of alkaloids (i.e., tomatine and dehydrotomatine) and transcripts related to biosynthesis of alkaloids were detected in type VII, but also in type I, IV and VI trichomes of this species [22]. Finally, the presence and density of glandular trichome types differs between Solanum species and/or cultivars [21,22,26] (see Table 2 for an overview of trichome morphology across Solanum spp.). In addition to the species, trichome density may also depend on the tissue [25] and environmental conditions [27]. Taken together, it is clear that different trichome types have distinct physiological properties and may have evolved due to different selection pressures.

Table 2. Distribution of trichome types in the section Lycopersicon of the genus Solanum.

\begin{tabular}{|c|c|c|c|c|c|c|c|c|}
\hline Species & $\begin{array}{l}\mathbf{I} \\
8 \\
8\end{array}$ & II & III & $\begin{array}{c}\text { IV } \\
\rho\end{array}$ & $\begin{array}{l}\mathbf{V} \\
\|\end{array}$ & VI & VII & VIII \\
\hline S. habrochaites & + & & + & + & & + & + & \\
\hline S. lycopersicum & + & & + & & + & + & + & + \\
\hline S. pennellii & & & & + & & + & & \\
\hline S. cheesmaniae, S. galapagense & & & & & + & & & \\
\hline S. pimpinellifolium & & + & & $+{ }^{b}$ & + & + & & \\
\hline $\begin{array}{l}\text { S. peruvianum, S. arcanum, } \\
\text { S. corneliomuelleri, S. huylasense }\end{array}$ & + & $+{ }^{a}$ & & & + & + & + & \\
\hline S. chilense & & & & & + & + & & + \\
\hline S. chmielewski & & & & & + & + & & \\
\hline S. neorickii & & & & & + & + & & \\
\hline
\end{tabular}

${ }^{\mathrm{a}}$ Described in the form glandulosum [20], formally $S$. corneliomuelleri; ${ }^{\mathrm{b}}$ Described in the accession TO-937 [28]. 


\section{Biosynthesis and Function of Glandular Trichome-Produced Compounds}

The plant epidermal surface represents the first barrier for pathogens and arthropod herbivores [29] to overcome after arrival on a plant. Therefore it may not come as a surprise that trichome density is one of the main factors correlating with resistance to herbivory [26,30]. The presence of trichomes is, however, not always beneficial for the plant, since trichomes may interfere with indirect defense by disturbing natural enemies of herbivores [26,31]. Trichomes can contribute to plant defense in different ways. Non-glandular trichomes can physically obstruct the movements of herbivorous arthropods over the plant surface or prevent herbivores to reach the surface with their mouthparts [32,33]. Moreover, arthropods may become entrapped in sticky and/or toxic exudates, such as acyl sugars or polyphenols, produced by glandular trichomes. Such polyphenols are quickly formed via oxidation when the contents from the glandular trichome heads are released as a result of insect-mediated rupturing of the glandular cuticle. The entrapped herbivores usually die as a result of starvation or of ingested toxins [34] or, in the case of small herbivores, of suffocation [35]. Alternatively, in some cases trichome-produced toxic compounds were found to be transported via the stalk to distal plant tissues, thereby increasing resistance of these tissues against plant attackers, as shown for pyrethrins in the plant pyrethrum (Tanacetum cinerariifolium). It appeared that such pyrethrins, produced by glandular trichomes on pyrethrum fruits, can be taken up by the seed and be transmitted to the seedlings, which lack glandular trichomes themselves, resulting in inhibition of fungal growth and of feeding by herbivorous arthropods [36]. Glandular trichomes, thus, function as important chemical barriers for plant parasites [30,37]. The main classes of secondary chemicals that have been found to be produced in trichomes include terpenoids [38], phenylpropenes [39] and flavonoids [40], methyl ketones [41], acyl sugars [42] and defensive proteins [37]. Although all of these compounds play a role in plant defense, both glandular and non-glandular trichomes may have many other functions as well, including attraction of pollinators [4,43], protection against UV due the presence of flavonoids and other UV-absorbing compounds in trichomes $[44,45]$, temperature regulation $[43,46]$ and reduction of water loss [46]. Furthermore, the ability of some plants to tolerate high levels of metals is correlated with their ability to sequester these compounds in their trichomes, as shown for the rough hawkbit (Leontodon hispidus) [47], which can sequester calcium, and tobacco (Nicotiana tabacum) which is able to secrete cadmium and zinc via its trichomes [48].

\subsection{Hormonal Regulation of Induced Defenses in Trichomes}

In the literature, often two forms of plant defense are discriminated. The first are the constitutive defenses, i.e., those defenses that are always present (such as trichomes), and the second are the induced defenses, which are activated or increased upon attack by herbivores or pathogens (such as some parts of the trichome metabolism). Typically, wounding and/or herbivore infestation activates the octadecanoid pathway, resulting in increasing levels of jasmonic acid (JA) which triggers the expression of defense genes, such as protease inhibitors (PIs), as well as the accumulation of secondary metabolites, like terpenoids [49]. Besides regulating herbivore-induced defense responses, JA is also linked with trichome formation, since JA biosynthesis and reception mutants in the cultivated tomato were shown to have less glandular trichomes $[23,50]$ while, in addition, herbivore feeding as well as 
JA treatment can give rise to increased trichome densities on newly formed leaves [51-53]. Furthermore, terpene emission can be induced in tomato glandular trichomes by spraying plants with JA [54] and protease inhibitors were shown to be induced in glandular trichomes when trichomes were ruptured by walking insects [50]. Apart from terpenoids [54] and defensive proteins [55], also acyl sugars [55] and alkaloids [56] can be induced in glandular trichomes by spraying plants with MeJA. Thus, JA is essential for induction of defenses in glandular trichomes. Downstream from hormonal regulation, production of many trichome metabolites is also under tight transcriptional control, thereby allowing for temporally regulated emission of, for example, plant volatiles [57,58].

\subsection{Terpenes}

With over 30,000 known structures, the terpenoids (or isoprenoids) represent the largest and structurally most diverse class of plant metabolites [59]. Terpenoids play important roles in primary plant metabolism, and provide the building blocks for pigments in photosynthesis (chlorophyll), for electron carriers in respiration (quinone) and for the phytohormones abscisic acid, cytokinins, gibberellins, strigolactones and the brassinosteroids [60,61]. The majority of terpenoids, however, are secondary metabolites and have functions related to plant defense [57]. Despite the immense variety of terpenoids, they are basically all assemblies of C5 isoprene units and produced in three consecutive steps, with a concomitant increase of their complexity and diversity. Since the biosynthesis of terpenoids has been reviewed extensively, we will only highlight the major biosynthetic steps here, for excellent reviews on this topic see e.g., [61-63]. In the cultivated tomato, terpenoids are produced in significant amounts by glandular type VI trichomes [24,25]. The first committed step of terpenoid biosynthesis comprises the formation of the universal C5 "building blocks" isopentenyl diphosphate (IPP) and its isomer dimethylallyl diphosphate (DMAPP). Both IPP and DMAPP are produced via the plastidial 2-C-methyl-D-erythritol 4-phosphate (MEP) pathway from pyruvate and glyceraldehyde-3-phosphate (Figure 2) [64,65]. Alternatively, IPP can be formed via the mevalonate (MVA) pathway from acetyl-CoA [66]. It has been suggested that the MVA pathway may partly occur in the peroxisomes, instead of the cytosol, but for tomato, this has not been shown [67]. Subsequent steps of terpenoid biosynthesis may take place at various subcellular locations, for instance, in the plastids, the (smooth) endoplasmic reticulum, mitochondria and/or the cytoplasm and, in line with this, different isoforms of the enzyme isopentenyl diphosphate isomerase (IDI), which catalyzes the isomerisation of IPP to DMAPP, can be found in the plastids, mitochondria and/or cytosol [68-70]. Furthermore, IPP and other terpenoid intermediates can also be shuttled between organelles [61,69]. Evidence for transport of DMAPP to other cellular compartments is lacking, or perhaps DMAPP is not transported at all [69]. In tobacco, the presence of chloroplasts in trichomes was shown to be necessary for production of diterpenes [71], thereby confirming the importance of these organelles in terpenoid biosynthesis.

In the second step of terpenoid biosynthesis, a single (C5) DMAPP serves as the substrate for successive head-to-tail condensations of one or more C5 IPP units. These linear chain elongation reactions are catalyzed by homo and/or heteromeric complexes of prenyltransferases [72]. Any of the intermediate products can be used as starting material for the synthesis of short (up to C20) isoprenyl diphosphates [61,73]. Interestingly, while most isoprenyl diphosphates are generated only in the cis $(Z)$ 
or trans $(E)$ conformation, some are produced in both isoforms [24,74]. The head-to-tail condensation reactions lead to the formation of $\mathrm{C} 10(E)$-geranyl diphosphate (GPP) and (Z)-neryl diphosphate (NPP), the C15 (E,E)-farnesyl diphosphate (FPP) and (Z,Z)-farnesyl diphosphate (Z,Z-FPP), the C20 (E,E,E)-geranylgeranyl diphosphate (GGPP) (Figure 2), and the longer oligoprenyl diphosphate (OPP; C25-45) and polyprenyl (C50-130) terpenoid precursor molecules. In the final step, the $(Z)$ - or $(E)$-isoprenyl diphosphates are converted into cyclic and acyclic terpenoids, catalyzed by a large enzyme family of terpene synthases (TPSs) [75,76]. The newly formed terpenoids are often subject to (multistep) secondary transformations, catalyzed by various enzymes in different organelles [62,77], leading to a wide range of structurally related terpenoids, which can be non-volatile like pigments and phytohormones, or volatile like the hemiterpenes (C5; derived from DMAPP), monoterpenes $(\mathrm{C} 10)$, sesquiterpenes $(\mathrm{C} 15)$, diterpenes $(\mathrm{C} 20)$, triterpenes $(\mathrm{C} 30)$, etc., and norterpenes (e.g., C11 and C16) $[61,63,78]$. Most terpene synthases are able to generate multiple products from a single substrate, which, together with the large size of TPS gene families, explains the diversity of terpenoids found in plants [62,77].

Terpenoids are major components of herbivore-induced volatile blends and they play an important role in the attraction of predators and parasitoids to herbivore-infested plants, a phenomenon known as indirect plant defense $[79,80]$. Indirect defenses mediated by plant volatiles have been reported from plant species with glandular trichomes, including model plants like cultivated tobacco [81], corn (Zea mays) [80], cotton [81] and cultivated tomato [49], but also from species without glandular trichomes, for example Arabidopsis (Arabidopsis thaliana) [82] and lima bean (Phaseolus lunatus) [83]. Terpenes may also play a role in direct defenses against pests as they can have a deterrent or repellent effect and at higher concentrations they are often toxic. For instance, in the wild potato (Solanum berthaultii), the release of the sesquiterpene (E)- $\beta$-farnesene from its glandular trichomes was shown to repel aphids (Myzus persicae) [84], while the parasitoids of this aphid, like the hymenopteran Diaeretiella rapae, were attracted to (E)- $\beta$-farnesene [85]. The sesquiterpenes 7 -epizingiberene and $R$-curcumene, produced by glandular type VI trichomes of some Solanum species [30], were shown to have a repellent effect on silverleaf whiteflies (Bemisia tabaci) [86,87]. Other herbivorous arthropods are affected as well by sesquiterpenes like zingiberene. For example, Carter et al. [88] showed that zingiberene is toxic to Colorado potato beetle (Leptinotarsa decemlineata) larvae and removal of sesquiterpenes by wiping $S$. habrochaites foliage with methanol increased the survival of beet armyworm larvae (Spodoptera exigua) from 0\% to 65\% [89]. In the South American tomato pinworm (Tuta absoluta), the presence of zingiberene was associated with a reduction in oviposition and feeding damage [90]. Finally, increased zingiberene levels were shown to correlate with increased repellency of the tobacco spider mite (Tetranychus evansi) [91].

\subsection{Phenylpropenes}

Like terpenoids, phenylpropanoids exhibit great structural diversity [92] and are emitted in significant amounts by plants, but both the quantity and the composition of the phenylpropanoid blend can markedly differ between species [93] and even cultivars [94]. Despite this structural diversity, three successive, very conserved, enzymatic conversions form the core of the phenylpropanoid biosynthetic pathway (Figure 2) [92]. The first committed step comprises the non-oxidative 
deamination of phenylalanine to trans-cinnamic acid, catalyzed by phenylalanine ammonia lyase $(P A L)$. Next, trans-cinnamic acid is hydroxylated to para-coumaric acid by cinnamate 4-hydroxylase $(\mathrm{C} 4 \mathrm{H})$. Finally, para-coumaric acid is activated by 4-coumarate CoA ligase $(4 C L)$, creating para-coumaroyl CoA, which is the general precursor for a wide range of products, including anthocyanins, flavonoids, lignin and phenylpropenes [57,92]. Together with terpenoids, the phenylpropenes are the major constituent of essential oils, which are secreted from glandular trichomes of many Lamiaceae [62]. In basil, for instance, eugenol and methylchavicol were shown to be predominantly synthesized and stored in the glandular trichomes [39].

Benzenoids, which are derived from trans-cinnamic acid by shortening of the side-chain [95,96], do not appear to be emitted from foliar glandular trichomes in large amounts and/or by many plant species. For instance, van Schie et al. [54] did not find evidence for production of methyl salicylate in tomato glandular trichomes and glandular trichomes of alfalfa (Medicago sativa) and hop (Humulus lupulus) emit only small amounts of benzenoids [97]. In contrast, methyl cinnamate, which is produced by methylation of trans-cinnamic acid, is synthesized in significant amounts by glandular trichomes [98].

Compared to the extensive knowledge on terpenoid biosynthesis, relatively little is known about the biosynthesis of eugenol, chavicol and their derivatives. The intermediate steps that follow after coumaric acid has been synthesized remain unclear, although an enzyme was identified in basil glandular trichomes that could catalyze the formation of eugenol by using coniferyl acetate and NADPH as substrates [99]. Furthermore, $O$-methyltransferases responsible for the last step in the formation of methylchavicol and methyleugenol have been characterized and were highly expressed in basil glandular trichomes [100].

Phenylpropenes are well known for their role in the attraction of pollinators. For example, methyleugenol from the orchid Bulbophyllum cheiri was shown to attract several fruit fly species (Bactrocera spp.) for pollination [101]. Furthermore, although the evidence is limited, some studies suggest that eugenol may contribute to plant resistance by negatively affecting plant parasites. For example, application of synthetic eugenol caused mortality and repellency in 4 Coleopteran species [102]. Moreover, also nematodes appeared to be susceptible to eugenol [103], as well as some fungi such as Cladosporium herbarum in which eugenol caused morphological deformations of the hyphae [104]. Taken together, it is clear that phenylpropenes fulfill dual roles, both in defense against herbivores, as well as in attraction of pollinators.

\subsection{Flavonoids}

Like the phenylpropenes, flavonoids are derivatives from the phenylpropanoid pathway. The first step in flavonoid biosynthesis comprises the condensation of one molecule of 4-coumaroyl-CoA and three molecules of malonyl-CoA, catalyzed by the enzyme chalcone synthase (CHS), followed by a cyclization reaction. In subsequent reactions, the flavone basic structure can be further modified by reductases, isomerases, hydroxylases, and glycosyltransferases, thereby forming the various subclasses of flavonoids, such as flavones, flavonols, flavandiols, anthocyanins, proanthocyanidins and isoflavonoids [105]. Accumulation of flavonoids in trichomes may serve to protect plants from UV-B [45] and there is evidence for sunlight-induced secretion of flavonoid glycosides by glandular trichomes of Phillyrea latifolia plants to protect them against damage induced by UV-A [106]. In 
S. habrochaites, it was shown that type I, IV and VI glandular trichomes contain methylated forms of the flavonol myricetin [107]. In the cultivated tomato, it was subsequently shown that the hairless ( $h l)$ mutation, which causes alterations in the morphology of all trichome types, also decreased accumulation of quercetin-trisaccharide, rutin, kaempferol-rhamnoside and 3-O-methylmyricetin in type VI glandular trichomes [25,108]. These and related phenolic compounds can inhibit growth of lepidopteran larvae [109]. Interestingly, trichomes from $h l$ leaves were also deficient in various sesquiterpenes, but contained wt levels of monoterpenes and acyl sugars [25]. As suggested by Kang et al. [25], perhaps $h l$ disrupts a cellular function required for the biosynthesis of sesquiterpenes and flavonoids, which are both synthesized in the cytosol.

\subsection{Methyl Ketones}

Methyl ketones constitute a class of fatty-acid derived volatile compounds that are very effective in protecting plants against pests [30]. Methyl ketones that are commonly found in plants have 7 to 15 carbons and include 2-heptanone, 2-nonanone, 2-undecanone, 2-tridecanone and 2-pentadecanone [41]. In $S$. habrochaites, methyl ketone biosynthesis was shown to proceed in two steps. The first step comprises the hydrolysis of 3-ketoacyl-acyl carrier protein intermediates, produced during fatty acid biosynthesis in chloroplasts (Figure 2). This step is catalyzed by an enzyme identified as methyl ketone synthase 2 (MKS2) [110,111]. The resulting 3-ketoacids are then decarboxylated in a reaction that is catalyzed by MKS1 [41,111].

In the 1980s, 2-tridecanone was identified as the major constituent of type VI trichomes of the wild tomato $S$. habrochaites f. glabratum [112]. Methyl ketones in this species were found in concentrations between 2700 and $5500 \mu \mathrm{g}$ per g fresh weight, whereas the cultivated tomato also contains 2-tridecanone, but in much smaller amounts, of up to $80 \mu \mathrm{g}$ per $\mathrm{g}$ fresh weight [113]. Williams et al. [112] demonstrated that 2-tridecanone was lethal to several herbivorous arthropods, including the tobacco hornworm (Manduca sexta) and the cotton aphid (Aphis gossypii). Tomato fruitworm (Helicoverpa zea) larvae were shown to be killed by the fume of $S$. habrochaites $\mathrm{f}$. glabratum and by pure 2-tridecanone [114]. Chatzivasileiadis et al. [115] showed that methyl ketones are toxic to the two-spotted spider mite upon contact. Trichome exudates and 2-tridecanone applied on artificial membranes inhibited feeding and caused mortality of the potato aphid (Macrosiphum euphorbiae) [116]. A second methyl ketone from tomato, identified as 2-undecanone [117], appeared to be less toxic since it did not negatively affect the potato aphid [116] nor did it cause larval mortality in the tobacco hornworm [117]. 2-undecanone did, however, cause increased mortality in the two-spotted spider mite [115] and it also increased mortality of pupae of the tomato fruitworm, and even more so when larvae of this species were reared on an artificial diet containing both 2-tridecanone and 2-undecanone [117]. 
Figure 2. Simplified schematic overview of the biosynthesis of the main secondary metabolites stored and/or secreted by tomato glandular trichome cells. Major pathway names are shown in red, key enzymes or enzyme complexes in purple, and stored and/or secreted compounds in blue. Metabolic routes are projected onto their subcellular location, however final modification reactions (e.g., glycosylations, acylations, methylations, hydroxylations), which can take place at various organelles, are not shown for clarity. Abbreviations used: 4CL, 4-coumarate CoA ligase; ACP, acyl carrier protein; BCKD, branched-chain keto acid dehydrogenase (multi-enzyme complex); $\mathrm{C} 4 \mathrm{H}$, cinnamate 4-hydroxylase; CoA, coenzyme A; DMAPP, dimethylallyl diphosphate; DTS, diterpene synthase; E4P, erythrose 4-phosphate; ER, endoplasmic reticulum; FAS, fatty acid synthesis, FPP, farnesyl diphosphate; GA3P, glyceraldehyde 3-phosphate; GGPP, geranylgeranyldiphosphate; GPP, geranyldiphosphate; IPP, isopentenyl diphosphate; Leu, leucine; the non-mevalonate pathway, also known as the 2-C-methyl-D-erythritol 4-phosphate (MEP) or 1-deoxy-D-xylulose 5-phosphate (DOXP) pathway; MTS, monoterpene synthase; MVA pathway, mevalonate pathway; NPP, neryldiphosphate; PAL, phenylalanine ammonia lyase; PEP, phosphoenolpyruvate; Phe, phenylalanine; STS, sesquiterpene synthase; Val, valine. Solid black arrows indicate established biochemical reactions. Dashed black arrows indicate hypothetical reactions. A single arrow does not necessarily represent a single enzymatic conversion.

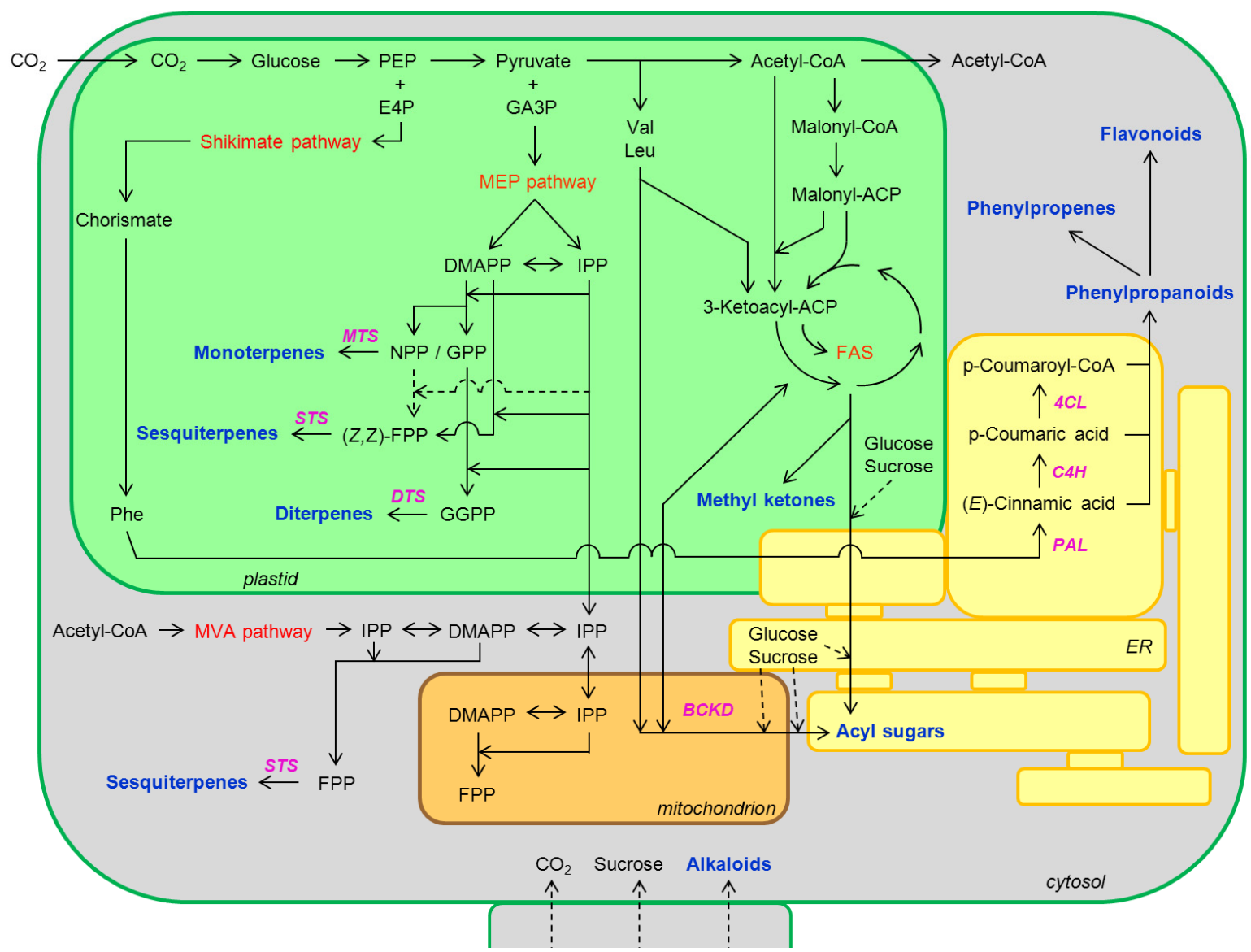




\subsection{Acyl Sugars}

Sugar esters, also called acyl sugars, are nonvolatile metabolites, produced [118] and stored in glandular trichomes of many Solanaceae, including Solanum, Nicotiana, Datura [42] and Petunia species [119]. These compounds are conjugates of sugars and aromatic or aliphatic fatty acids and a significant fraction of these are exuded onto the surface of aerial organs, in the case of the wild tomato Solanum pennellii up to $20 \%$ of the plant's leaf dry weight [120]. Acyl sugar biosynthesis is especially well studied in tomato $[118,121]$ and tobacco $[118,122]$ species. The backbone of acyl sugars consist of a sugar, predominantly sucrose or glucose, or sometimes a sugar-alcohol, predominantly sorbitol of xylitol, to which one or more straight or branched chain fatty acids, which are usually methyl-branched, are esterified. Depending on the number of acyl groups, i.e., the free hydroxyl groups in the sugar, most of these sugar esters are mono-, di- or tri-acyl sugars [35] and are formed via $O$-acylation. For example, type IV glandular trichomes of $S$. pennellii exude a mixture of 2,3,4-O-tri-acyl-glucoses [123], 3',3,4-O-tri-acyl-sucrose and 3',3,4,6-O-tetra-acyl-sucrose polyesters, which have both straight and branched chains, ranging in length from 2 to 12 carbons, that are formed prior to acetylation to glucose and sucrose $[9,124,125]$. The branched- or straight-chained fatty acid acyl moieties of the glucose esters of $S$. pennellii are derived from branched-chain amino acids (i.e., Val, Leu, and Ile) [124]. In Solanum and Datura species, elongation of fatty acids is mediated via fatty acid synthase (FAS), while in tobacco and petunia this elongation occurs via $\alpha$-ketoacid elongation [42]. Biosynthesis and elongation of branched fatty acids involves the branched-chain keto acid dehydrogenase (BCKD) protein complex which generates activated acyl-CoA esters from branched-chain keto acid precursors [118] but how these acyl-CoA esters are exactly used for synthesis of acyl sugars is still unclear [121]. In S. pennellii, the acylation steps require sequential action of a glucosyl transferase, which forms the first acyl sugar intermediate, and an acyl transferase that catalyzes the further additions of fatty acids to the backbone [126,127]. Finally, also an acyltransferase (AT2) has been identified that catalyzes the transfer of the acetyl group found in the tetra-acyl sucroses of the cultivated tomato [121]. Expression of AT2 was shown to be specific for the tip cells of type IV glandular trichomes of an S. lycopersicum $x$ S. penelli introgression line [121].

Acyl sugars may be directly toxic to herbivores, but they are also excellent emulsifiers and surfactants and may easily stick to arthropod cuticles thereby immobilizing or suffocating arthropods [1,35]. Wagner et al. [1] reported that aphids upon contact with tobacco trichomes are rapidly "coated" by trichome-produced sugar esters, thereby entrapping the insect and preventing it from further moving around. Staining with Rhodamine B revealed that the highest concentrations of sugar esters are present at the joints of the aphid's antennae and legs where entry of toxins into the body is likely to occur most easily [1]. Also, it was shown that acyl sugars can deter or repel herbivores, such as the potato aphid. Structure and activity studies revealed that acyl glucoses and acyl sucroses were equally repellent to the aphid and differences in the length of the fatty acid chain did not influence repellency [128]. However, according to Puterka et al. [35] the toxic properties of synthetic acyl sugars depend both on sugar backbone and fatty acid chain length, and different acyl sugars caused different mortalities in pear psyllids (Cacopsylla pyricola), tobacco aphids (Myzus nicotianae), tobacco hornworms and spider mites. Furthermore, in tomato the density of glandular trichomes and the amount of acyl sugars were shown to correlate with resistance to whiteflies and spider 
mites [129-131]. Other arthropods that were shown to be negatively affected by acyl sugars include the tomato fruitworm, the beet armyworm (Spodoptera exigua) [132] and the leafminer (Liriomyza trifollii) [133]. Apart from functioning as direct defense, acyl sugars may also function in indirect defenses. Although perhaps counter-intuitive, it appeared that freshly hatched larvae of three Lepidopteran herbivore species, i.e., the beet armyworm, the tobacco hornworm and the African cotton leafworm (Spodoptera littoralis), preferred to feed from trichomes as their first meal and were not negatively affected by this. However, it was found that this behavior could backfire depending on the ecological setting of the animals, as the high concentration of ingested and digested acyl sugars caused these larvae to release a distinct odor of branched-chain fatty acids from their body and frass. This odor appeared sufficient to betray their whereabouts to one of their natural enemies, the omnivorous ant Pogonomyrmex rugosus [122].

\subsection{Defensive Proteins}

Apart from secondary metabolites, trichomes are also able to produce significant amounts of proteins with defensive functions, such as proteinase inhibitors (PIs) [134], polyphenol oxidases (PPOs) [135] and phylloplanins [37]. PIs can be either constitutively expressed (e.g., in flowers) or induced upon wounding or herbivory in leaves and their trichomes [53] and induced PIs slow down the growth of herbivores upon ingestion [136,137] probably via inhibition of digestive proteinases in the herbivore gut. PPOs constitute a class of enzymes that utilize molecular oxygen for the oxidation of mono- and $O$-diphenols to $O$-dihydroxyquinones [138]. Significant amounts of PPOs can accumulate in trichomes. For instance, in glandular trichomes of the wild potato, PPO can constitute up to $70 \%$ of the total protein content [139]. In the cultivated tomato, there is evidence that some isoforms of the PPO family are expressed in specific trichome types and not in others [140]. For example, PPO-A and $\mathrm{C}$ are expressed in type I and IV trichomes, as well as PPO-E and F while, in contrast, type VI trichomes express PPO-D, E and F, but not A and C. PPOs and their substrates are compartmentalized probably to prevent spontaneous reactions. In the head cells of tomato type VI trichomes, PPOs are stored in leucoplasts whereas their phenolic substrates are present in the vacuoles [140]. When the tissue is damaged, for instance by walking herbivores, the PPOs will mix with vacuolar content of the head cell and rapidly oxidize $o$-dihydroxyphenolics to the corresponding $O$-quinones [141]. These quinones, in turn, are highly reactive molecules that covalently bind to nucleophilic - $\mathrm{NH} 2$ and $-\mathrm{SH}$ groups of molecules such as amino acids and proteins, thereby reducing the availability of essential amino acids to the herbivores and/or the digestibility of proteins [141,142], or perhaps interfering directly with enzymes. Apart from reducing the nutritive quality of leaves to herbivores [141], trichome-PPOs have also been implicated in resistance to plant pathogenic bacteria. Overexpression of a PPO from potato (Solanum tuberosum) in cultivated tomato yielded transgenic plants that were much more resistant to the bacterial pathogen Pseudomonas syringae [143,144], and in dandelion (Taraxacum officinale) suppression of $P P O-2$ via silencing increased plant susceptibility to $P$. syringae [145]. Glandular trichomes may also actively secrete proteins, as shown in cultivated tobacco, where proteins can be deposited on the leaf surface through pores that are present in the cuticle of short glandular trichomes [37,146] which are reminiscent of tomato type VII trichomes [147]. These secreted proteins, termed tobacco phylloplanins, inhibited spore germination and leaf infection by the 
oomycete pathogen Peronospora tabacina [37]. It has been suggested that these proteins, possibly in interaction with other secreted trichome-produced compounds, are broadly distributed over the leaf surface of tobacco plants, thereby providing constitutive resistance against diseases [148].

\section{Identification of Biochemical Pathways in Glandular Trichomes}

Interest in trichome-produced compounds, combined with technical breakthroughs in analytical equipment and the possibility of applying genomic approaches, has greatly increased the understanding of the biochemical pathways that operate in trichomes, as well as the products they generate. Sequencing of Expressed Sequence Tag (EST) libraries generated from mRNA from isolated trichomes has resulted in large databases, which, in combination with metabolite profile analysis of glandular trichomes and proteomics, has led to a much more detailed general insight into the biosynthesis of these specialized metabolites than obtained previously via chemical-analytical methods [16].

Based on analyses of EST databases, it has been suggested that trichomes operate mostly as a self-supporting system [9] and have highly active biochemical pathways for both primary and secondary metabolism [9]. In glandular trichomes of tomato and tobacco, genes encoding enzymes and proteins related to photosynthesis and carbon fixation are significantly expressed [149,150], indicating that at least some of the carbon necessary for secondary metabolism can be fixed within trichome cells [22]. Earlier studies in cultivated tobacco had also indicated that glandular trichomes possibly can fix carbon and produce sugar and diterpenoids (i.e., duvatrienediol) independent from the rest of the plant, although a role for additional carbon imported from the tissues below the trichome cannot be excluded [151,152]. In mint, however, photosynthesis-related genes were not expressed [153], indicating significant differences between plant species or between trichome types. It has been suggested that the total amount of secondary metabolites produced by glandular cells could be related to their capacity to fix carbon [154] since exudates from photosynthetically active glandular cells can constitute up to $20 \%$ of the leaf dry weight biomass in wild Solanaceae $[118,120]$ while exudates from species with leucoplasts instead of chloroplasts in their trichomes, like the Lamiaceae and Fabaceae, contribute less than $2 \%$ to the leaf dry weight [39,62,154,155]. Leucoplasts are non-pigmented plastid-type organelles specialized for de novo biosynthesis of (precursors for) the metabolites that often will be secreted [18]. However, photosynthetically active glandular trichomes are probably supplemented with carbon substrates (e.g., $\mathrm{CO}_{2}$, sucrose, glucose) as well, because their own primary metabolism is most likely incapable of meeting the huge carbon demands [22,154]. Besides carbon, other compounds, like nitrogen, phosphate and micronutrients, are required for metabolism as well. According to Schilmiller et al. [9], import of amino acids into trichomes is minimal, begging the question of how trichomes acquire their nitrogen necessary for the large amount of proteins synthesized in trichomes [37,139]. Possibly, nitrogen can be recycled by amino transferases in glandular trichomes [9], but it cannot be excluded that nitrogen and other essential substances are imported via the trichome stalk, as well.

EST analyses have played an important role in identifying enzymes of trichome secondary metabolism, for instance, in the synthesis of geraniol [156] and eugenol [99] in basil; the synthesis of methyl ketones [41,110], monoterpenes [24] and sesquiterpenes [74,157,158] in Solanum species; and, xanthohumol synthesis in hops [159]. In mint, the first species from which trichome-specific ESTs 
were sequenced, $35 \%$ of the sequences were estimated to be involved in secondary metabolism of which $25 \%$ in monoterpene biosynthesis [153]. Genes from primary metabolism pathways were found to be highly expressed in mint trichomes, with, for example, genes of the glycolytic pathway, the pentose phosphate and the oxidative phosphorylation pathway accounting for more than $35 \%$ of all ESTs as well as lipid transfer protein (LTP) homologs (32\%), which probably play a role in metabolite transport [16,153] since, in tobacco, the trichome-specific LTP1 gene was shown to play a role in the secretion of terpenoids [160]. In contrast, in basil, more than $25 \%$ of glandular trichome ESTs were related to the phenylpropanoid pathway or involved in phenylpropene biosynthesis [39]. In basil, tobacco and cultivated tomato, proteomics studies on glandular trichomes have been carried out as well, allowing for a detailed comparison between their transcriptomes and proteomes [e.g., 157,161] and this led to new insights in the posttranscriptional regulation of trichome metabolism [161]. Included among the many proteins (1552 in total) identified in tomato trichomes were: enzymes involved in the MEP pathway; enzymes involved in synthesis of the flavonoid compound rutin; enzymes that take part in synthesis of volatile aldehydes (e.g., lipoxygenase $\mathrm{C}$ and hydroperoxide lyase; HPL); and, defense-related proteins, such as PPOs [157]. Moreover, a sesquiterpene synthase was identified that produces $\beta$-caryophyllene and $\alpha$-humulene from $E$, $E$-farnesyl diphosphate in glandular trichomes of leaves, but not in glandular trichomes of the stem [157], while other sesquiterpene synthases are preferentially expressed in other organs, for instance, in glandular trichomes of the stem [76,158]. This indicates that, depending on the plant organ, there can be differences between if and when genes are expressed in glandular trichomes and thus which metabolites they accumulate.

\section{Trichome Engineering to Increase Plant Resistance}

The preparation of trichome-specific EST databases did not only facilitate the discovery and characterization of genes in trichome biosynthetic pathways, but also made it more feasible to engineer the production of specific biocides in trichomes [147]. Most engineering strategies are not designed to obtain expression of a transgene exclusively in a target tissue, such as a trichome, and/or at specific moments, but make use of a construct in which the transgene is fused behind the general $35 \mathrm{~S}$ promoter and is expressed either via stable transformation [15] or via virus-induced gene silencing $[121,162]$. Although this can give rise to pleiotropisms [163], such strategies clearly can suffice to manipulate key metabolic steps in the target biocide's metabolic route. Cultivated tobacco, and its related wild species Nicotiana sylvestris and Nicotiana tomentosiformis, produce diterpenes, exist in two forms: the macrocyclic cembranoids, including the cembratrien-diols (CBT-diols) and their precursors the cembratrien-ols (CBT-ols), and the bicyclic labdanoids. Cultivated tobacco and N. tomentosiformis produce both labdanoids and cembranoids, while $N$. sylvestris only produces the latter group of compounds. These diterpenes are produced in large amounts and, specifically, in the glandular capitate trichomes of the plant, and some of these labdanoids contribute to plant resistance to pests, making tobacco an ideal target for terpenoid metabolic engineering [147]. For example, in cultivated tobacco, downregulation of a trichome-specific CYP450, a CBT-ol hydroxylase, via antisense suppression, led to reduction of CBT-diol levels but promoted the levels of its insecticidal precursor CBT-ol, thereby increasing plant resistance to the red aphid (Myzus nicotianae) [164]. Thus, silencing genes can be 
used to increase levels of compounds with biocidal properties in trichomes, thereby enhancing a plant's resistance. The large amount of data collected on trichome-specific gene expression $[16,157,158]$ also made it possible to tailor gene overexpression more specifically by using trichome-specific promoters instead of the $35 \mathrm{~S}$ promoter. The promoter of the trichome-specific CBT-ol hydroxylase gene [164] was one of the first trichome-specific promoters that has been isolated [165] and in N. sylvestris several cis-regulatory elements of a CBT-ol synthase promoter were identified, required for specific expression in the secretory cells of glandular trichomes [166] and the CBT-ol synthase promoters have been used to produce novel diterpenoids [167] and heterologous sesquiterpenes in N. sylvestris [74]. Moreover, from squash (Cucurbita maxima) Anandan et al. [168] isolated the promoters of a protease inhibitor family and found that one of these was trichome-specific while Liu et al. [169] cloned the cotton fiber-specific LTP3 promoter and fused it to B-glucuronidase (GUS), and demonstrated that expression of this construct in transgenic tobacco plants indeed was specific for its trichomes. However, the possibilities to modify plant-pest interactions by altering trichome chemistry via herbivore- or pathogen-specific promoters have hardly been addressed. Van Schie et al. [54] characterized a trichome-specific linalool synthase, called MTS1, induced by wounding the plant defense-hormone JA and by spider mite feeding and, potentially, the promoters of such herbivore-inducible trichome-specific genes can be used to re-engineer trichome based resistance. Finally, Bleeker et al. [170] provided proof of this concept by demonstrating that expressing 7-epizingiberene synthase from $S$. habrochaites fused to the MTS1 promoter [54], together with Z-Z-farnesyl-diphosphate synthase fused to the MKS1 promoter [111], specifically in the glandular trichomes of the cultivated tomato can improve resistance against herbivores, including whiteflies and spider mites.

In conclusion, glandular trichomes are an important first line of defense against herbivorous insects and pathogens. Tremendous progress in the availability of genomic data has allowed for the discovery of genes in various biosynthetic pathways involved in trichome-produced compounds. However, the full potential of trichomes has not been exploited even remotely since plant secondary metabolism is complex and multilayered while our knowledge on the precise actions of the different members of large gene families and on the rate-limiting steps in pathways is still too incomplete to make the outcome of such manipulations easily predictable. However, it is evident that via breeding or genetic engineering - by using, for example, trichome-specific promoters - we will develop a stronger grip on how to obtain the desired levels of biocides in a tissue-specific manner. Thus, these minute glandular trichomes may soon prove to be the ideal vehicles for targeted modification of the versatile secondary metabolism of many plant species to customize essential oil production and enhance biocide-based protection of crops.

\section{Acknowledgments}

We thank Jan van Arkel (IBED, University of Amsterdam) for taking photographs of the tomato glandular trichomes and Eleni Spyropoulou (Plant Physiology, University of Amsterdam) for critical reading of the manuscript. JMA is funded via NWO Earth and Life Sciences (ALW) TOP (854.11.005) and BJCS via NWO Earth and Life Sciences (ALW) together with TTI Green Genetics (828.08.001). 


\section{Conflict of Interest}

The authors declare no conflict of interest.

\section{References}

1. Wagner, G.J.; Wang, E.; Shepherd, R.W. New approaches for studying and exploiting an old protuberance, the plant trichome. Ann. Bot. 2004, 93, 3-11.

2. Payne, W.W. A glossary of plant hair terminology. Brittonia 1978, 30, 239-255.

3. Reis, C.; Sajo, M.G.; Stehmann, J.R. Leaf structure and taxonomy of Petunia and Calibrachoa (Solanaceae). Braz. Arch. Biol. Techol. 2002, 45, 59-66.

4. Werker, E. Trichome diversity and development. In Plant Trichomes; Hallahan, D.L., Gray, J.C., Eds.; Academic Press: New York, NY, USA, 2000; p. 1.

5. Mathur, J.; Chua, N. Microtubule stabilization leads to growth reorientation in Arabidopsis trichomes. Plant Cell 2000, 12, 465-477.

6. Schnittger, A.; Hülskamp, M. Trichome morphogenesis: A cell-cycle perspective. Phil. Trans. R. Soc. Lond. B 2002, 357, 823-826.

7. Larkin, J.C.; Brown, M.L.; Schiefelbein, J. How do cells know what they want to be when they grow up? Lessons from epidermal patterning in Arabidopsis. Annu. Rev. Plant Biol. 2003, 54, 403-430.

8. Fahn, A. Structure and function of secretory cells. In Plant Trichomes; Hallahan, D.L., Gray, J.C., Eds.; Academic Press: New York, NY, USA, 2000; p. 37.

9. Schilmiller, A.L.; Last, R.L.; Pichersky, E. Harnessing plant trichome biochemistry for the production of useful compounds. Plant J. 2008, 54, 702-711.

10. Duke, S.O.; Canel, C.; Rimando, A.M.; Tellez, M.R.; Duke, M.V.; Paul, R.N. Current and potential exploitation of plant glandular trichome productivity. Adv. Bot. Res. 2000, 31, 121-151.

11. Aharoni, A.; Jongsma, M.A.; Kim, T.; Ri, M.; Giri, A.P.; Verstappen, F.W.A.; Schwab, W.; Bouwmeester, H.J. Metabolic engineering of terpenoid biosynthesis in plants. Phytochem. Rev. 2006, 5, 49-58.

12. Weathers, P.J.; Arsenault, P.R.; Covello, P.S.; McMickle, A.; Teoh, K.H.; Reed, D.W. Artemisinin production in Artemisia annua: Studies in planta and results of a novel delivery method for treating malaria and other neglected diseases. Phytochem. Rev. 2011, 10, 173-183.

13. Mellon, J.E.; Zelaya, C.A.; Dowd, M.K.; Beltz, S.B.; Klich, M.A. Inhibitory effects of gossypol, gossypolone, and apogossypolone on a collection of economically important filamentous fungi. J. Agric. Food Chem. 2012, 60, 2740-2745.

14. Dayan, F.E.; Duke, S.O. Trichomes and root hairs: Natural pesticide factories. Pestic. Outlook 2003, 4, 175-178.

15. Lange, B.M.; Mahmoud, S.S.; Wildung, M.R.; Turner, G.W.; Davis, E.M.; Lange, I.; Baker, R.C.; Boydston, R.A.; Croteau, R.B. Improving peppermint essential oil yield and composition by metabolic engineering. Proc. Natl. Acad. Sci. USA 2011, 108, 16944-16949.

16. Tissier, A. Glandular trichomes: What comes after expressed sequence tags? Plant J. 2012, 70, $51-68$. 
17. Maffei, M.E. Sites of synthesis, biochemistry and functional role of plant volatiles. S. Afr. J. Bot. 2010, 76, 612-631.

18. Turner, G.W.; Gershenzon, J.; Croteau, R.B. Distribution of peltate glandular trichomes on developing leaves of peppermint. Plant Physiol. 2000, 124, 655-663.

19. Fahn, A. Secretory tissues in vascular plants. New Phytol. 1988, 108, 229-257.

20. Luckwill, L.C. The genus Lycopersicon: A historical, biological and taxonomic survey of the wild and cultivated tomato. Aberd. Univ. Stud. 1943, 120, 1-44.

21. Channarayappa, S.G.; Muniyappa, V.; Frist, R.H. Resistance of Lycopersicon species to Bemisia tabaci, a tomato leaf curl virus vector. Can. J. Bot. 1992, 70, 2184-2192.

22. McDowell, E.T.; Kapteyn, J.; Schmidt, A.; Li, C.; Kang, J.; Descour, A.; Shi, F.; Larson, M.; Schilmiller, A.; An, L.; et al. Comparative functional genomic analysis of Solanum glandular trichome types. Plant Physiol. 2011, 155, 524-539.

23. Li, L.; Zhao, Y.; McCaig, B.C.; Wingerd, B.A.; Wang, J.; Whalon, M.E.; Pichersky, E.; Howe, G.A. The tomato homolog of CORONATINE-INSENSITIVE1 is required for the maternal control of seed maturation, jasmonate-signaled defense responses, and glandular trichome development. Plant Cell 2004, 16, 126-143.

24. Schilmiller, A.L.; Schauvinhold, I.; Larson, M.; Xu, R.; Charbonneau, A.L.; Schmidt, A.; Wilkerson, C.; Last, R.L.; Pichersky, E. Monoterpenes in the glandular trichomes of tomato are synthesized from a neryl diphosphate precursor rather than geranyl diphosphate. Proc. Natl. Acad. Sci. USA 2009, 106, 10865-10870.

25. Kang, J.; Shi, F.; Jones, A.D.; Marks, M.D.; Howe, G.A. Distortion of trichome morphology by the hairless mutation of tomato affects leaf surface chemistry. J. Exp. Bot. 2010, 61, 1053-1064.

26. Simmons, A.T.; Gurr, G.M. Trichomes of Lycopersicon species and their hybrids: Effects on pests and natural enemies. Agric. Forest Entomol. 2005, 7, 265-276.

27. Wilkens, R.T.; Shea, G.O.; Halbreich, S.; Stamp, N.E. Resource availability and the trichome defenses of tomato plants. Oecologia 1996, 106, 181-191.

28. Fernández-Muñoz, R.; Salinas, M.; Álvarez, M.; Cuartero, J. Inheritance of resistance to two-spotted spider mite and glandular leaf trichomes in wild tomato Lycopersicon pimpinellifolium (Jusl.) Mill. J. Am. Soc. Hortic. Sci. 2003, 128, 188-195.

29. Fordyce, J.A.; Agrawal, A.A. The role of plant trichomes and caterpillar group size on growth and defence of the pipevine swallowtail Battus phineor. J. Anim. Ecol. 2001, 70, 997-1005.

30. Kennedy, G.G. Tomato, pests, parasitoids, and predators: Tritrophic interactions involving the genus Lycopersicon. Annu. Rev. Entomol. 2003, 48, 51-72.

31. Wei, J.; Yan, L.; Ren, Q.; Li, C.; Ge, F.; Kang, L.E. Antagonism between herbivore-induced plant volatiles and trichomes affects tritrophic interactions. Plant Cell Environ. 2012, doi:10.1111/j.1365-3040.2012.02575.x.

32. Cardoso, M.Z. Herbivore handling of a plant's trichome: The case of Heliconius charithonia (L.) (Lepidoptera: Nymphalidae) and Passiflora lobata (Killip) Hutch. (Passifloraceae). Neotrop. Entomol. 2008, 37, 247-252.

33. Pott, C.; McLoughlin, S.; Shunqing, W.; Friis, E.M. Trichomes on the leaves of Anomozamites villosus sp. nov. (Bennettitales) from the Daohugou beds (Middle Jurassic), Inner Mongolia, China: Mechanical defence against herbivorous arthropods. Rev. Paleobot. Palyno. 2012, 169, 48-60. 
34. Simmons, A.T.; Gurr, G.M.; McGrath, D.; Martin, P.M.; Nicol, H.I. Entrapment of Helicoverpa armigera (Hübner) (Lepidoptera: Noctuidae) on glandular trichomes of Lycopersicon species. Austr. J. Entomol. 2004, 43, 196-200.

35. Puterka, G.J.; Farone, W.; Palmer, T.; Barrington, A. Structure-function relationships affecting the insecticidal and miticidal activity of sugar esters. J. Econ. Entomol. 2003, 96, 636-644.

36. Ramirez, A.M.; Stoopen, G.; Menzel, T.R.; Gols, R.; Bouwmeester, H.J.; Dicke, M.; Jongsma, M.A. Bidirectional secretions from glandular trichomes of Pyrethrum enable immunization of seedlings. Plant Cell 2012, 24, 4252-4265.

37. Shepherd, R.W.; Bass, W.T.; Houtz, R.L.; Wagner, G.J. Phylloplanins of tobacco are defensive proteins deployed on aerial surfaces by short glandular trichomes. Plant Cell 2005, 17, 1851-1861.

38. Gershenzon, J.; Dudareva, N. The function of terpene natural products in the natural world. Nat. Chem. Biol. 2007, 3, 408-414.

39. Gang, D.R.; Wang, J.; Dudareva, N.; Nam, K.H.; Simon, J.E.; Lewinsohn, E.; Pichersky, E. An investigation of the storage and biosynthesis of phenylpropenes in sweet basil. Plant Physiol. 2001, 125, 539-555.

40. Treutter, D. Significance of flavonoids in plant resistance: A review. Environ. Chem. Lett. 2006, 4, 147-157.

41. Fridman, E.; Wang, J.; Iijima, Y.; Froehlich, J.E.; Gang, D.R.; Ohlrogge, J.; Pichersky, E. Metabolic, genomic and biochemical analyses of glandular trichomes from the wild tomato species Lycopersicon hirsutum identify a key enzyme in the biosynthesis of methyl ketones. Plant Cell 2005, 17, 1252-1267.

42. Kroumova, A.B.; Wagner, G.G. Different elongation pathways in the biosynthesis of acyl groups of trichome exudate sugar esters from various solanaceous plants. Planta 2003, 216, 1013-1021.

43. Johnson, J.B. Plant pubescence: An ecological perspective. Bot. Rev. 1975, 41, 233-258.

44. Karabourniotis, G.; Kotsabassidis, D.; Manetas, Y. Trichome density and its protective potential against ultraviolet-B radiation damage during leaf development. Can. J. Bot. 1995, 73, 376-383.

45. Karabourniotis, G.; Kofidis, G.; Fasseas, C.; Liakoura, V.; Drossopoulos, I. Polyphenol deposition in leaf hairs of Olea europaea (Oleaceae) and Quercus ilex (Fagaceae). Am. J. Bot. 1998, 85, 1007-1012.

46. Ehleringer, J. Ecology and ecophysiology of leaf pubescence in North American desert plants. In Biology and Chemistry of Plant Trichomes; Rodriguez, E., Healey, P.L., Mehta, I., Eds.; Plenum Press: New York, NY, USA, 1984; pp. 113-132.

47. De Silva, D.L.R.; Hetherington, A.M.; Mansfield, T.A. Where does all the calcium go? Evidence of an important regulatory role for trichomes in two calcicoles. Plant Cell Environ. 1996, 19, 880-886.

48. Sarret, G.; Harada, E.; Choi, Y.; Isaure, M.; Geoffroy, N.; Fakra, S.; Markus, M.A.; Birschwilks, M.; Clemens, S.; Manceau, A. Trichomes of tobacco excrete zinc as zinc-substituted calcium carbonate and other zinc-containing compounds. Plant Physiol. 2006, 141, 1021-1034.

49. Kant, M.R.; Ament, K.; Sabelis, M.W.; Haring, M.A.; Schuurink, R.C. Differential timing of spider mite-induced direct and indirect defenses in tomato plants. Plant Physiol. 2004, 135, 483-495. 
50. Peiffer, M.; Tooker, J.F.; Luthe, D.S.; Felton, G.W. Plants on early alert: Glandular trichomes as sensors for insect herbivores. New Phytol. 2009, 184, 644-656.

51. Traw, M.B.; Dawson, T.E. Differential induction of trichomes by three herbivores of black mustard. Oecologia 2002, 131, 526-532.

52. Boughton, A.J.; Hoover, K.; Felton, G.W. Methyl jasmonate application induces increased densities of glandular trichomes on tomato, Lycopersicon esculentum. J. Chem. Ecol. 2005, 31, 2211-2216.

53. Tian, D.; Tooker, J.; Peiffer, M.; Chung, S.; Felton, G.W. Role of trichomes in defense against herbivores: Comparison of herbivore response to woolly and hairless trichome mutants in tomato (Solanum lycopersicum). Planta 2012, 236, 1053-1066.

54. Van Schie, C.C.N.; Haring, M.A.; Schuurink, R.C. Tomato linalool synthase is induced in glandular trichomes by jasmonic acid. Plant Mol. Biol. 2007, 64, 251-263.

55. Hare, J.D.; Walling, L.L. Constitutive and jasmonate-inducible traits of Datura wrightii. J. Chem. Ecol. 2006, 32, 29-47.

56. Laue, G.; Preston, C.A.; Baldwin, I.T. Fast track to the trichome: Induction of $N$-acyl nornicotines precedes nicotine induction in Nicotiana repanda. Planta 2000, 210, 510-514.

57. Dudareva, N.; Negre, F.; Nagegowda, D.A.; Orlova, I. Plant volatiles: Recent advances and future perspectives. Crit. Rev. Plant Sci. 2006, 25, 417-440.

58. Kant, M.R.; Bleeker, P.M.; Van Wijk, M.; Schuurink, R.C.; Haring, M.A. Plant volatiles in defence. In Advances in Botanical Research; Van Loon, L.C. Ed.; Academic Press: Burlington, VT, USA, 2009; Volume 51, pp. 613-666.

59. Connolly, J.D.; Hill, R.A. Dictionary of Terpenoids; Chapman and Hall: London, UK, 1991.

60. Matusova, R.; Rani, K.; Verstappen, F.W.A.; Franssen, M.C.R.; Beale, M.H.; Bouwmeester, H.J. The strigolactone germination stimulants of the plant-parasitic Striga and Orobanche spp. are derived from the carotenoid pathway. Plant Physiol. 2005, 139, 920-934.

61. Vranová, E.; Coman, D.; Gruissem, W. Structure and dynamics of the isoprenoid pathway network. Mol. Plant 2012, 5, 318-333.

62. Croteau, R.B.; Davis, E.M.; Ringer, K.L.; Wildung, M.R. (-)-Menthol biosynthesis and molecular genetics. Naturwissenschaften 2005, 92, 562-577.

63. Tholl, D. Terpene synthases and the regulation, diversity and biological roles of terpene metabolism. Curr. Opin. Plant Biol. 2006, 9, 297-304.

64. Hoeffler, J.F.; Herrerlin, A.; Grosdemange-Billiard, C.; Bach, T.J.; Rohmer, M. Isoprenoid biosynthesis in higher plants and in Escherichia coli. On the branching in the methylerythritol phosphate pathway and the independent biosynthesis of isopentenyl diphosphate and dimethylallyl diphosphate. Biochem J. 2002, 366, 573-583.

65. Rodríguez-Concepcíon, M.; Boronat, A. Elucidation of the methylerythritol phosphate pathway for isoprenoid biosynthesis in bacteria and plastids. A metabolic milestone achieved through genomics. Plant Physiol. 2002, 130, 1079-1089.

66. McGarvey, D.J.; Croteau, R. Terpenoid metabolism. Plant Cell 1995, 7, 1015-1026.

67. Tholl, D.; Lee, S. Terpene specialized metabolism in Arabidopsis thaliana. Arabidopsis Book 2011, 9, doi:10.1199/tab.0143. 
68. Nakamura, A.; Shimada, H.; Masuda, T.; Ohta, H.; Takamiya, K.-I. Two distinct isopentenyl diphosphate isomerases in cytosol and plastid are differentially induced by environmental stresses in tobacco. FEBS Lett. 2001, 506, 61-64.

69. Phillips, M.A.; D’Auria, J.C.; Gershenzon, J.; Pichersky, E. The Arabidopsis thaliana type I isopentenyl diphosphate isomerases are targeted to multiple subcellular compartments and have overlapping functions in isoprenoid biosynthesis. Plant Cell 2008, 20, 677-696.

70. Sun, J.; Zhang, Y.-Y.; Liu, H.; Zou, Z.; Zhang, C.-J.; Zhang, X.-H.; Li, H.-X.; Ye, Z.-B. A novel cytoplasmic isopentenyl diphosphate isomerase gene from tomato (Solanum lycopersicum): Cloning, expression, and color complementation. Plant Mol. Biol. Rep. 2010, 28, 473-480.

71. Nielsen, M.T.; Akers, C.P.; Järlfors, U.E.; Wagner, G.J.; Berger, S. Comparative ultrastructural features of secreting and nonsecreting glandular trichomes of two genotypes of Nicotiana tabacum L. Bot. Gaz. 1991, 152, 13-22.

72. Wang, K.C.; Ohnuma, S.-I. Isoprenyl diphosphate synthases. Biochim. Biophys. Acta 2000, 1529, 33-48.

73. Dewick, P.M. The biosynthesis of $\mathrm{C}_{5}-\mathrm{C}_{25}$ terpenoid compounds. Nat. Prod. Rep. 2002, 19, 181-222.

74. Sallaud, C.; Rontein, D.; Onillon, S.; Jabès, F.; Duffé, P.; Giacalone, C.; Thoraval, S.; Escoffier, C.; Herbette, G.; Leonhardt, N.; et al. A novel pathway for sesquiterpene biosynthesis from Z,Z-farnesyl pyrophosphate in the wild tomato Solanum habrochaites. Plant Cell 2009, 21, 301-317.

75. Chen, F.; Tholl, D.; Bohlmann, J.; Pichersky, E. The family of terpene synthases in plants: A mid-size family of genes for specialized metabolism that is highly diversified throughout the kingdom. Plant J. 2011, 66, 212-229.

76. Falara, V.; Akhtar, T.A.; Nguyen, T.T.H.; Spyropoulou, E.A.; Bleeker, P.M.; Schauvinhold, I.; Matsuba, Y.; Bonini, M.E.; Schilmiller, A.L.; Last, R.L.; et al. The tomato terpene synthase gene family. Plant Physiol. 2011, 157, 770-789.

77. Degenhardt, J.; Köllner, T.G.; Gershenzon, J. Monoterpene and sesquiterpene synthases and the origin of terpene skeletal diversity in plants. Phytochemistry 2009, 70, 1621-1637.

78. Tholl, D.; Sohrabi, R.; Huh, J.-H.; Lee, S. The biochemistry of homoterpenes-common constituents of floral and herbivore-induced plant volatile bouqets. Phytochemistry 2011, 72, 1635-1646.

79. Dicke, M.; Sabelis, M.W. How plants obtain predatory mites as bodyguards. Neth. J. Zool. 1988, 38, 148-165.

80. Schnee, C.; Köllner, T.G.; Held, M.; Turlings, T.C.J.; Gershenzon, J.; Degenhardt, J. The products of a single maize sesquiterpene synthase form a volatile defense signal that attracts natural enemies of maize herbivores. Proc. Natl. Acad. Sci. USA 2006, 103, 1129-1134.

81. De Moraes, C.M.; Lewis, W.J.; Pare, P.W.; Alborn, H.T.; Tumlinson, J.H. Herbivore-infested plants selectively attract parasitoids. Nature 1998, 393, 570-573.

82. Van Poecke, R.M.P.; Posthumus, M.A.; Dicke, M. Herbivore-induced volatile production by Arabidopsis thaliana leads to attraction of the parasitoid Cotesia rubecula: Chemical, behavioral and gene-expression analysis. J. Chem. Ecol. 2001, 27, 1911-1928. 
83. Dicke, M. Local and systemic production of volatile herbivore-induced terpenoids - their role in plant-carnivore mutualism. J. Plant Physiol. 1994, 143, 465-472.

84. Gibson, R.W.; Pickett, J.A. Wild potato repels aphids by release of aphid alarm pheromone. Nature 1983, 302, 608-609.

85. Beale, M.H.; Birkett, M.A.; Bruce, T.J.A.; Chamberlain, K.; Field, L.M.; Huttley, A.K.; Martin, J.L.; Parker, R.; Phillips, A.L.; Pickett, J.A.; et al. Aphid alarm pheromone produced by transgenic plants affects aphid and parasitoid behavior. Proc. Natl. Acad. Sci. USA 2006, 103, 10509-10513.

86. Bleeker, P.M.; Diergaarde, P.J.; Ament, K.; Guerra, J.; Weidner, M.; Schutz, S.; De Both, M.T.J.; Haring, M.A.; Schuurink, R.C. The role of specific tomato volatiles in tomato-whitefly interaction. Plant Physiol. 2009, 151, 925-935.

87. Bleeker, P.M.; Diergaarde, P.J.; Ament, K.; Schütz, S.; Johne, B.; Dijkink, J.; Hiemstra, H.; de Gelder, R.; de Both, M.T.J.; Sabelis, M.W.; et al. Tomato-produced 7-epizingiberene and R-curcumene act as repellents to whiteflies. Phytochemistry 2011, 72, 68-73.

88. Carter, C.D.; Sacalis, J.N.; Gianfagna, T.J. Zingiberene and resistance to Colorado potato beetle in Lycopersicon hirsutum f. hirsutum. J. Agric. Food Chem. 1989, 37, 206-210.

89. Eigenbrode, S.D.; Trumble, J.T.; Millar, J.G.; White, K.K. Topical toxicity of tomato sesquiterpenes to the beet armyworm and the role of these compounds in resistance derived from an accession of Lycopersicon hirusutum f. typicum. J. Agric. Food Chem. 1994, 42, 807-810.

90. De Azevedo, S.M.; Faria, M.V.; Maluf, W.R.; de Oliveira, A.C.B.; De Freitas, J.A. Zingiberene-mediated resistance to the South American tomato pinworm derived from Lycopersicon hirsutum var. hirsutum. Euphytica 2003, 134, 347-351.

91. Maluf, W.R.; Campos, G.A.; Cardoso, C.M. Relationships between trichome types and spider mite (Tetranychus evansi) repellence in tomatoes with respect to foliar zingiberene contents. Euphytica 2001, 121, 73-80.

92. Vogt, T. Phenylpropanoid biosynthesis. Mol. Plant 2010, 3, 2-20.

93. Knudsen, J.T.; Eriksson, R.; Gershenzon, J.; Ståhl, B. Diversity and distribution of floral scent. Bot. Rev. 2006, 72, 1-120.

94. Iijima, Y.; Davidovich-Rikanati, R.; Fridman, E.; Gang, D.R.; Bar, E.; Lewinsohn, E.; Pichersky, E. The biochemical and molecular basis for the divergent patterns in the biosynthesis of terpenes and phenylpropenes in the peltate glands of three cultivars of basil. Plant Physiol. 2004, 136, 3724-3736.

95. Boatright, J.; Negre, F.; Chen, X.; Kish, C.M.; Wood, B.; Peel, G.; Orlova, I.; Gang, D.; Rhodes, D.; Dudareva, N. Understanding in vivo benzenoids metabolism in petunia petal tissue. Plant Physiol. 2004, 135, 1993-2011.

96. Van Moerkercke, A.; Schauvinhold, I.; Pichersky, E.; Haring, M.A.; Schuurink, R.C. A plant thiolase involved in benzoic acid biosynthesis and volatile benzenoid production. Plant J. 2009, 60, 292-302.

97. Yang, D.S.; Sumner, L.W. Metabolic profiling of trichomes from potato leafhopper susceptible and resistant alfalfa lines. Available online: http://www.planttrichome.org (accessed on 1 November 2012). 
98. Kapteyn, J.; Qualley, A.; Xie, Z.; Fridman, E.; Dudareva, N.; Gang, D.R. Evolution of cinnamate/p-coumarate carboxylmethyltransferases and their role in the biosynthesis of methylcinnamate. Plant Cell 2007, 19, 3212-3229.

99. Koeduka, T.; Fridman, E.; Gang, D.R.; Vassão, D.G.; Jackson, B.L.; Kish, C.M.; Orlova, I.; Spassova, S.M.; Lewis, N.G.; Noel, J.P.; et al. Eugenol and isoeugenol, characteristic aromatic constituents of spices, are biosynthesized via reduction of coniferyl acohol ester. Proc. Natl. Acad. Sci. USA 2006, 103, 10128-10133.

100. Gang, D.R.; Lavid, N.; Zubieta, C.; Chen, F.; Beuerle, T.; Lewinsohn, E.; Noel, J.P.; Pichersky, E. Characterization of phenylpropene $O$-methyltransferases from sweet basil: Facile change of substrate specificity and convergent evolution within a plant $O$-methyltransferase family. Plant Cell 2002, 14, 505-519.

101. Tan, K.H.; Nishida, R.; Toong, Y.C. Floral synomone of a wild orchid, Bulbophyllum cheiri, lures Bactrocera fruit flies for pollination. J. Chem. Ecol. 2002, 28, 1161-1172.

102. Obeng-Ofori, D.; Reichmuth, C. Bioactivity of eugenol, a major component of essential oil of Ocimum suave (Wild.) against four species of stored-product Coleoptera. Int. J. Pest Manag. 1997, 43, 89-94.

103. Sangwan, N.; Verman, B.; Verma, K.; Dhindsa, K. Nematicidal activity of some essential plant oils. Pest Sci. 1990, 28, 331-335.

104. Adams, S.; Weidenborner, M. Mycelial deformations of Cladosporium herbarum due to the application of eugenol or carvacrol. J. Essential Oil Res. 1996, 8, 535-540.

105. Ferrer, J.; Austin, M.B.; Stewart, C., Jr.; Noel, J.P. Structure and function of enzymes involved in the biosynthesis of phenylpropanoids. Plant Physiol. Biochem. 2008, 46, 356-370.

106. Tattini, M.; Gravano, E.; Pinelli, P.; Mulinacci, N.; Romani, A. Flavonoids accumulate in leaves and glandular trichomes of Phillyrea latifolia exposed to excess solar radiation. New Phytol. 2000, 148, 69-77.

107. Schmidt, A.; Li, C.; Shi, F.; Jones, A.D.; Pichersky, E. Polymethylated myricetin in trichomes of the wild tomato species Solanum habrochaites and characterization of trichome-specific 3'/5'and 7/4'-myricetin O-methyltransferases. Plant Physiol. 2011, 155, 1999-2009.

108. Kang, J.; Liu, G.; Shi, F.; Jones, A.D.; Beaudry, R.M.; Howe, G.A. The tomato odorless-2 mutant is defective in trichome-based production of diverse specialized metabolites and broad-spectrum resistance to insect herbivores. Plant Physiol. 2010, 154, 262-272.

109. Duffey, S.S.; Isman, M.B. Inhibition of insect larval growth by phenolics in glandular trichomes of tomato leaves. Experientia 1981, 37, 574-576.

110. Ben-Israel, I.; Yu, G.; Austin, M.B.; Bhuiyan, N.; Auldridge, M.; Nguyen, T.; Schauvinhold, I.; Noel, J.P.; Pichersky, E.; Fridman, E. Multiple biochemical and morphological factors underlie the production of methylketones in tomato. Plant Physiol. 2009, 151, 1952-1964.

111. Yu, G.; Nguyen, T.T.H.; Guo, Y.; Schauvinhold, I.; Auldridge, M.E.; Bhuiyan, N.; Ben-Israel, I.; Iijima, Y.; Fridman, E.; Noel, J.P.; et al. Enzymatic functions of wild tomato methylketone synthases 1 and 2. Plant Physiol. 2010, 154, 67-77.

112. Williams, W.G.; Kennedy, G.G.; Yamamoto, R.T.; Thacker, J.D.; Bordner, J. 2-Tridecanone: A naturally occurring insecticide from the wild tomato Lycopersicon hirsutum f. glabratum. Science 1980, 207, 888-889. 
113. Antonious, G.F. Production and quantification of methyl ketones in wild tomato accessions. J. Environ. Sci. Health B 2001, 36, 835-848.

114. Dimock, M.B.; Kennedy, G.G. The role of glandular trichomes in the resistance of Lycopersicon hirsutum f. glabratum to Heliothis zea. Entomol. Expl. Appl. 1983, 33, 263-268.

115. Chatzivasileiadis, E.A.; Sabelis, M.W. Toxicity of methyl ketones from tomato trichomes to Tetranychus urticae Koch. Exp. Appl. Acarol. 1997, 21, 473-484.

116. Musetti, L.; Neal, J.J. Toxicological effect of Lycopersicon hirsutum f. glabratum and behavioral response of Macrosiphum euphorbia. J. Chem. Ecol. 1997, 23, 1321-1332.

117. Farrar, R.R.; Kennedy, G.G. 2-Undecanone, a constituent of the glandular trichomes of Lycopersicon hirsutum f. glabratum: Effects on Heliothis zea and Manduca sexta growth and survival. Entomol. Exp. Appl. 1987, 43, 17-23.

118. Slocombe, S.P.; Schauvinhold, I.; McQuinn, R.P.; Besser, K.; Welsby, N.A.; Harper, A.; Aziz, N.; Li, Y.; Larson, T.R.; Giovannoni, J.; et al. Transcriptomic and reverse genetic analyses of branched-chain fatty acid and acyl sugar production in Solanum pennellii and Nicotiana benthamiana. Plant Physiol. 2008, 148, 1830-1846.

119. Chortyk, O.T.; Kays, S.J.; Teng, Q. Characterization of insecticidal sugar esters of Petunia. J. Agric. Food Chem. 1997, 45, 270-275.

120. Fobes, J.F.; Mudd, J.B.; Marsden, M.P.F. Epicuticular lipid accumulation on the leaves of Lycopersicon pennellii (Corr.) D'Arcy and Lycopersicon esculentum Mill. Plant Physiol. 1985, 77, 567-570.

121. Schilmiller, A.L.; Charbonneau, A.L.; Last, R.L. Identification of a BAHD acetyltransferase that produces protective acyl sugars in tomato trichomes. Proc. Natl. Acad. Sci. USA 2012, 109, 16377-16382.

122. Weinhold, A.; Baldwin, I.T. Trichome-derived $O$-acyl sugars are a first meal for caterpillars that tags them for predation. Proc. Natl. Acad. Sci. USA 2011, 108, 7855-7859.

123. Burke, B.A.; Goldsby, G.; Mudd, J.B. Polar epicuticular lipids of Lycopersicon pennellii. Phytochemistry 1987, 26, 2567-2571.

124. Walters, D.S.; Steffens, J.C. Branched chain amino acid metabolism in the biosynthesis of Lycopersicon pennellii glucose esters. Plant Physiol. 1990, 93, 1544-1551.

125. Li, A.X.; Eannetta, N.; Ghangas, G.S.; Steffens, J.C. Glucose polyester biosynthesis. Purification and characterization of a glucose acyltransferase. Plant Physiol. 1999, 121, 453-460.

126. Ghangas, G.S.; Steffens, J.C. UDP glucose:fatty acid transglucosylation and transacylation in triacylglucose biosynthesis. Proc. Natl. Acad. Sci. USA 1993, 90, 9911-9915.

127. Li, A.X.; Steffens, J.C. An acyltransferase catalyzing the formation of diacylglucose is a serine carboxipeptidase-like protein. Proc. Natl. Acad. Sci. USA 2000, 97, 6902-6907.

128. Goffreda, J.C.; Mutschler, M.A.; Avé, D.A.; Tingey, W.M.; Steffens, J.C. Aphid deterrence by glucose esters in glandular trichome exudate of the wild tomato, Lycopersicon pennellii. J. Chem. Ecol. 1989, 15, 2135-2147.

129. Saeidi, Z.; Mallik, B.; Kulkarni, R.S. Inheritance of glandular trichomes and two-spotted spider mite resistance in cross Lycopersicon esculentum "Nandi" and L. pennellii "LA2963". Euphytica 2007, 154, 231-238. 
130. Alba, J.M.; Montserrat, M.; Fernández-Muñoz, R. Resistance to the two-spotted spider mite (Tetranychus urticae) by acylsucroses of wild tomato (Solanum pimpinellifolium) trichomes studied in a recombinant inbred line population. Exp. Appl. Acarol. 2009, 47, 35-47.

131. Rodríguez-López, M.J.; Garzo, E.; Bonani, J.P.; Fereres, A.; Fernández-Muñoz, R.; Moriones, E. Whitefly resistance traits derived from the wild tomato Solanum pimpinellifolium affect the preference and feeding behavior of Bemisia tabaci and reduce the spread of tomato yellow leaf curl virus. Phytopathology 2011, 101, 1191-1201.

132. Juvik, J.A.; Shapiro, J.A.; Young, T.E.; Mutschler, M.A. Acylglucoses from wild tomatoes alter behavior and reduce growth and survival of Helicoverpa zea and Spodoptera exigua (Lepidoptera: Noctuidae). J. Econ. Entomol. 1994, 87, 482-492.

133. Hawthorne, D.J.; Shapiro, J.A.; Tingey, W.M.; Mutschler, M.A. Trichome-borne and artificially applied acylsugars of wild tomato deter feeding and oviposition of the leafminer Liriomyza trifolii. Entomol. Exp. Appl. 1992, 65, 65-73.

134. Liu, J.; Xia, K.F.; Zhu, J.C.; Deng, Y.G.; Huang, X.L.; Hu, B.L.; Xu, X.; Xu, Z.F. The nightshade proteinase inhibitor IIb gene is constitutively expressed in glandular trichomes. Plant Cell Physiol. 2006, 47, 1274-1284.

135. Yu, H.; Kowalski, S.P.; Steffens, J.C. Comparison of polyphenol oxidase expression in glandular trichomes of Solanum and Lycopersicon species. Plant Physiol. 1992, 100, 1885-1890.

136. Steppuhn, A.; Baldwin, I.T. Resistance management in a native plant: Nicotine prevents herbivores from compensating for plant protease inhibitors. Ecol. Lett. 2007, 10, 499-511.

137. Hartl, M.; Giri, A.P.; Kaur, H.; Baldwin, I.T. Serine protease inhibitors specifically defend Solanum nigrum against generalist herbivores but do not influence growth and development. Plant Cell 2010, 22, 4158-4175.

138. Vaughn, K.C.; Lax, A.R.; Duke, S.O. Polyphenol oxidase: The chloroplast oxidase with no established function. Physiol. Plant 1988, 72, 659-665.

139. Kowalski, S.P.; Eannetta, N.T.; Hirzel, A.T.; Steffens, J.C. Purification and characterization of polyphenol oxidase from glandular trichomes of Solanum berthaultii. Plant Physiol. 1992, 100, $677-684$.

140. Thipyapong, P.; Joel, D.M.; Steffens, J.C. Differential expression and turnover of the tomato polyphenol oxidase gene familiy during vegetative and reproductive development. Plant Physiol. 1997, 113, 707-718.

141. Felton, G.W.; Donato, K.; del Vecchio, R.J.; Duffey, S.S. Activation of plant foliar oxidases by insect feeding reduces nutritive quality of foliage for noctuid herbivores. J. Chem. Ecol. 1989, 15, 2667-2694.

142. Felton, G.W.; Donato, K.K.; Broadway, R.M.; Duffey, S.S. Impact of oxidized plant phenolics on the nutrional quality of dietary protein to a noctuid herbivore, Spodoptera exigua. J. Insect Physiol. 1992, 38, 277-285.

143. Li, L.; Steffens, J.C. Overexpression of polyphenol oxidase in transgenic tomato plants results in enhanced bacterial disease resistance. Planta 2002, 215, 239-247.

144. Thipyapong, P.; Hunt, M.D.; Steffens, J.C. Antisense downregulation of polyphenol oxidase results in enhanced disease susceptibility. Planta 2004, 220, 105-117. 
145. Richter, C.; Dirks, M.E.; Gronover, C.S.; Prüfer, D.; Moerschbacher, B.M. Silencing and heterologous expression of ppo-2 indicate a specific function of a single polyphenol oxidase isoform in resistance of Dandelion (Taraxacum officinale) against Pseudomonas syringae pv. tomato. Mol. Plant Microbe Int. 2012, 25, 200-210.

146. Shepherd, R.W.; Wagner, G.J. Phylloplane proteins: Emerging defenses at the aerial frontline. Trends Plant Sci. 2007, 12, 51-56.

147. Tissier, A. Trichome specific expression: Promoters and their applications. In Transgenic plants - Advances and limitations; Çiftçi, Y.O., Ed.; InTech: Rijeka, Croatia, 2012; pp. 353-378.

148. Shepherd, R.W.; Wagner, G.J. Fungi and leaf surfaces. In Biocomplexity of plant-fungal interactions; Southworth, D., Ed.; John Wiley \& Sons: Chichester, West Sussex, UK, 2012; p. 131.

149. Harada, E.; Kim, J.; Meyer, A.J.; Hell, R.; Clemens, S.; Choi, Y. Expression profiling of tobacco leaf trichomes identifies genes for biotic and abiotic stress. Plant Cell Physiol. 2010, 51, $1627-1637$.

150. Cui, H.; Zhang, S.; Yang, H.; Ji, H.; Wang, X. Gene expression profile analysis of tobacco leaf trichomes. BMC Plant Biol. 2011, 11, 76-86.

151. Keene, C.K.; Wagner, G.J. Direct demonstration of duvatrienediol biosynthesis in glandular heads of tobacco trichomes. Plant Physiol. 1985, 79, 1026-1032.

152. Kandra, L.; Wagner, G.J. Studies of the site and mode of biosynthesis of tobacco trichome exudate components. Arch. Biochem. Biophys. 1988, 265, 425-432.

153. Lange, B.M.; Wildung, M.R.; Stauber, E.J.; Sanchez, C.; Pouchnick, D.; Croteau, R. Probing essential oil biosynthesis and secretion by functional evaluation of expressed sequence tags from mint glandular trichomes. Proc. Natl. Acad. Sci. USA 2000, 97, 2934-2939.

154. Wagner, G.J. Secreting glandular trichomes: More than just hairs. Plant Physiol. 1991, 96, 675-679.

155. Franceschi, V.R.; Giaquinta, R.T. Glandular trichomes of soybean leaves: Cytological differentiation from initiation through senescence. Bot. Gaz. 1983, 144, 175-184.

156. Iijima, Y.; Gang, D.R.; Fridman, E.; Lewinsohn, E.; Pichersky, E. Characterization of geraniol synthase from the peltate glands of sweet basil. Plant Physiol. 2004, 134, 370-379.

157. Schilmiller, A.L.; Miner, D.P.; Larson, M.; McDowell, E.; Gang, D.R.; Wilkerson, C.; Last, R.L. Studies of a biochemical factory: Tomato trichome deep expressed sequence tag sequencing and proteomics. Plant Physiol. 2010, 153, 1212-1223.

158. Bleeker, P.M.; Spyropoulou, E.A.; Diergaarde, P.J.; Volpin, H.; De Both, M.T.J.; Zerbe, P.; Bohlmann, J.; Falara, V.; Matsuba, Y.; Pichersky, E.; et al. RNA-seq discovery, functional characterization, and comparison of sesquiterpene synthases from Solanum lycopersicum and Solanum habrochaites trichomes. Plant Mol. Biol. 2011, 77, 323-336.

159. Nagel, J.; Culley, L.K.; Lu, Y.; Liu, E.; Matthews, P.D.; Stevens, J.F.; Page, J.E. EST analysis of hop glandular trichomes identifies an $O$-methyltransferase that catalyzes the biosynthesis of xanthohumol. Plant Cell 2008, 20, 186-200.

160. Choi, Y.; Lim, S.; Kim, H.; Han, J.; Lee, M.; Yang, Y.; Kim, J.; Kim, Y. Tobacco NtLTP1, a glandular-specific lipid transfer protein, is required for lipid secretion from glandular secretions. Plant J. 2012, 70, 480-491. 
161. Xie, Z.; Kapteyn, J.; Gang, D.R. A systems biology investigation of the MEP/terpenoid and shikimate/phenylpropanoid pathways points to multiple levels of metabolic control in sweet basil glandular trichomes. Plant J. 2008, 54, 349-361.

162. Besser, K.; Harper, A.; Welsby, N.; Schauvinhold, N.; Slocombe, S.; Li, Y.; Dixon, R.A.; Broun, P. Divergent regulation of terpenoid metabolism in the trichomes of wild and cultivated tomato species. Plant Physiol. 2009, 149, 499-514.

163. Wang, S.; Wang, J.; Yu, N.; Li, C.; Luo, B.; Gou, J.; Wang, L.; Chen, X. Control of plant trichome development by a cotton fiber MYB gene. Plant Cell 2004, 16, 2323-2334.

164. Wang, E.; Wang, R.; DeParasis, J.; Loughrin, J.H.; Gan, S.; Wagner, G.J. Suppression of a P450 hydroxylase gene in plant trichome glands enhances natural-product-based aphid resistance. Nature Biotech. 2001, 19, 371-374.

165. Wang, E.; Gan, S.; Wagner, G.J. Isolation and characterization of the CYP71D16 trichome-specific promoter of Nicotiana tabacum L. J. Exp. Bot. 2002, 53, 1891-1897.

166. Ennajdaoui, H.; Vachon, G.; Giacalone, C.; Besse, I.; Sallaud, C.; Herzog, M.; Tissier, A. Trichome specific expression of the tobacco (Nicotiana sylvestris) cembratrien-ol synthase genes is controlled by both activating and repressing cis-regions. Plant Mol. Biol. 2010, 73, 673-685.

167. Rontein, D.; Onillon, S.; Herbette, G.; Lesot, A.; Werck-Reichhart, D.; Sallaud, C.; Tissier, A. CYP725A4 from yew catalyzes complex structural rearrangement of taxa-4(5),11(12)-diene into the cyclic ether 5(12)-oxa-3(11)-cyclotaxane. J. Biol. Chem. 2008, 283, 6067-6075.

168. Anandan , A.; Gatehouse, L.N.; Marshall, R.K.; Murray, C.; Christeller, J.T. Two highly homologous promoters of a squash aspartic protease inhibitor (SQAPI) multigene family exhibit differential expression in transgenic tobacco phloem and trichome cells. Plant Mol. Biol. Rep. 2009, 27, 355-364.

169. Liu, H.; Creech, R.G.; Jenkins, J.N.; Ma, D. Cloning and promoter analysis of the cotton lipid transfer protein gene Ltp3. Biochim. Biophys. Acta 2000, 1487, 106-111.

170. Bleeker, P.M.; Mirabella, R.; Diergaarde, P.J.; Van Doorn, A.; Tissier, A.; Kant, M.R.; Prins, M.; de Vos, M.; Haring, M.A.; Schuurink, R.C. Improved herbivore resistance in cultivated tomato with the sesquiterpene biosynthetic pathway from a wild relative. Proc. Natl. Acad. Sci. USA 2012, dio:10.1073/pnas.1208756109.

(C) 2012 by the authors; licensee MDPI, Basel, Switzerland. This article is an open access article distributed under the terms and conditions of the Creative Commons Attribution license (http://creativecommons.org/licenses/by/3.0/). 